\title{
Accountability and the University: is Whirl to be King?
}

\author{
"Zeus is detbroned, and Whirl is King." - Aristophones, The Clouds \\ William M. Sibley*
}

* Dr:W. M. Sibley is Vice-President (Planning and Special Assignments), The University of Manitoba. This paper was presented originally at the Annual Conference of The Canadian Society for the Study of Higher Education beld at McGill University in May 1972.

\section{Circumscription of the Topic}

With a view to making my task more manageable, I must severely limit the scope of my remarks. I shall confine my reflections principally to "multiversities" : institutions of 10,000 or more, with a full range of traditional and professional schools and faculties. In all probability, my remarks will not be at all applicable (or applicable only in part) to institutions of considerably smaller scale. Nor, to my regret, am I able to comment intelligently on Francophone universities in Quebec and elsewhere, though I do suspect that in what I have to say there may nonetheless be a certain degree of transferability to such institutions. Finally, for lack of both time and knowledge, I shall not address myself to the problems of other institutions of post-escondary education such as technical and community colleges.

\section{The Malaise of the Contemporary University}

Given these limitations, let me begin with some references to the current university scene. This can hardly be described as stable, serene and confident. It is only a few years since the much-heralded Duff-Berdahl Report led to major revisions in the structures and operations of university government. Most of its recommendations (e.g., the "opening" of senate and other bodies, the creation of academically controlled senates, the election of students to senate and students and faculty members to boards of governors) were initially seen by proponents and opponents alike to be charged with great significance. Yet the results in practice seem to have been frustrating to almost 
all concerned - to students, to faculty, and certainly to administrators. After some early flurries of interest, hardly any one not a member bothers to attend the now opened meetings of senates and boards, there to hear some local Demosthenes or Cicero deliver his Philippic or Catilinarian Oration, Against the Administration. In a number of universities, seats on senates are frequently not even contested by faculty members or by students. There is a wide-spread feeling amongst academic that somehow little of substance in university affairs has been changed by these reforms; the younger staff, in particular, appear to have lost most of their interest in participation in senate affairs. They will tell you that academics on senate are "co-opted", indeed corrupted, by the administrative members - even though at many institutions the so-called "administrators" may be heavily out-numbered by elected faculty. Curricular reform - a project which used to stir up every university at least once a decade - attracts less interest and concern : there seem to be left few true believers to espouse its efficacy and significance. About many of these traditional interests of the academic world there is prevalent a mood of apathy, a feeling of frustration and of impotence, as the observations of Adell and Carter confirm. ${ }^{1}$ The energies of many of our younger academics (they go on to remark) are turned elsewhere, chiefly to the matter of collective bargaining as a possible response to the "tenure crisis" now continent-wide in its scope.

At a later point, I shall return to comment briefly upon the meaning of developments of this latter type, in which litigation and adversary relationships bid fair to feature so prominently. Here I wish merely to remark that, whatever the merits of the Duff-Berdahl reform movement have been, and whatever academics may now think of the outcome, the profound changes which these reforms have introduced into university structures and operations, overlaid with other changes now occurring or impending, have produced in our universities a serious loss of capacity to cope with the new and threatening circumstances in which we find ourselves. Foremost amongst these circumstances is the current attitude of governments and of large segments of the public to the university enterprise.

\section{The Demand for Accountability}

In order to obtain a better insight both into the internal predicament of our universities and into the now acute problem of their relationships with government, I want to isolate for some rudimentary analysis and explication the term "accountability". This has, very suddenly, become an "in" word : almost faddish. There is apparently no reference to it as a major theme of discussion in the Education Index prior to June, 1970. Now there is a positive flood of articles about accountability; newspaper editorials and government pronouncements invariably invoke it. It has almost the status of an incantation. Like other popular words ("alienation", "relevance", etc.) it both points to and hides a very complex reality. I shall therefore next explore the term's meaning and some of the more obvious conditions of its usefulness and applicability. 


\section{The Mandate of Accounitability}

What is it, first of all, that we mean by the term "accountability" ? ${ }^{2}$ In some senses (though not all) it is equivalent to "responsible". "To be responsible", in the context before us, means "to be answerable legally and morally for the discharge of a duty, trust or debt". "To be answerable" carries with it the notion of some person $X$, standing in certain relations to a person $Y$. In the "discharge of his duty, trust or debt", $X$ is liable to be "called to account" by $Y$; that is, obliged to justify to $Y$ what he has done or has failed to do. If $X$ refuses to give such an account, or if $Y$ finds his account wanting in some respect, then $Y$ is empowered to inflict upon $X$ an appropriate penalty or "sanction", or to request some other authority so to do. "Accountability" thus entails a context of autbority of some kind, of a structuring of "offices" within some juridicial or institutional framework.

For example, a university dean is generally considered to be accountable to his president (a) for the implementation of some general faculty or university policy, or (b) for some achievement of some general objective. He may be charged (say) with the implementation in his area of some university policy on the conduct of examinations; or charged with the attainment of such an objective as the upgrading of research capability in his faculty. He may also be charged (c) with the execution of certain explicit directives, e.g., with respect to the handling of the financial affairs of his faculty.

But here we touch on an important point about the significance of the concept and practice of accountability. In so far as directives (e.g., for the processing of financial accounts) become more and more explicit and rule-governed, they ipso-facto become more and more amenable to execution not by a dean but by a clerk - and in principle approach amenability to handling by machines. We invent and operate with the concept of accountability primarily because there are so many matters (like "policies" and "objectives") which require the exercise of discretion and of judgment, and cannot be caught in any network of explicit rules no matter how fine. A machine or a slave (in the Aristotelian sense of a "living instrument") cannot be held accountable. In this context "judgment" typically entails the presence of some norm by which in the discharge of the functions of his office our dean (or comparable officer) is supposed to be guided. Sometimes such norms or standards are the subjects of reasonably explicit comment. Frequently, however, they are implicit only: i.e., they must be gathered from the context of the office and the institution. Thus, in all probability a dean is never told: "Do not hire incompetent staff"; but a dean who sought to justify a bad appointment to his president by saying : "But you never told me not to hire incompetent staff" is not advancing a very plausible excuse. From the above remarks it is plain that the assumption of office (and hence accountability) by the dean entails on his part certain burdens and risks. He must interpret through his actions certain norms which are themselves not fully interpreted - nor indeed capable of such interpretation prior to action, He must give specific, concrete embodiment to some abstract idea or ideal. 
Now, if the concept of accountability is to be of any practical value, several conditions are necessary. (1) The first condition is that it be made operative. $X$ must at appropriate times be "called to account". Occasionally, the concept must be operated as far as the actual imposition of some sanction, such as censure or removal from office.

(2) Secondly, the operation of the concept must be within the bounds of what is rational. To be rational is to adopt means that will effectively realize your ends whatever they are. It is not rational for an institution to subject an academic or administrative officer to two mutually conflicting authorities or centres of power. Suppose it to be insisted, for instance, that a dean is fully accountable (in the sense explained) both to a faculty council all of whose members are true believers in some full-blown version of "participatory democracy" and to his president for one and the same action ; but the council and the president happen to take diametrically opposed views of the appropriateness of that action. In such a case, the dean becomes the locus of a conflict or struggle for power for which the institution has found no resolution. An institution which has no will or no means to achieve conflict resolution is to that extent ineffective in achieving its purpose. We then have an incipient split into two (or more) institutions or organizations. Temporary or minor conflicts are no doubt unavoidable and endurable. If, however, they become serious or prolonged, the institution as a rational and coherent structure is clearly undergoing dissolution.

I remarked above that in accepting office the dean assumes not only certain obvious burdens but also risks. From a moral point of view, $X$ in exchange for such burdens and risks acquire certain rights - the violation of which is unreasonable. This (3) is my third necessary condition : the concept of accountability must operate within the bounds of what is reasonable. For instance, is is not at all reasonable to impose sanctions on $X$ if he is trapped by fundamental confusions or ambiguities about the nature of his office and its authority as well as its duties. (Of course, it is not rational either - for the very good reason, at least in academic circles, that the dean is going to quit on you : persuading good people to accept headships and deanships is becoming steadily more difficult.) Rights and duties are correlative. Nor is it reasonable to hold an officer accountable if the policies and objectives which he is supposed to implement are so vague and obscure as to be wholly uninterpretable. Nor, thirdly, is it reasonable to hold him accountable if he has no power, or inadequate power, to implement such policies as are reasonably clear, either explicitly or implicitly.

\section{The Defeat of Accountability Within the University: From Legitimacy to Litigation}

From the above discussion I want to draw out for comment factors which I shall speak of as "conditions operating to defeat accountability" within the university. (Strictly speaking, I suppose, they are conditions which defeat the point of the purpose of accountability; but for the sake of the brevity I shall speak elliptically.) I shall comment on three of these: (1) the general erosion in the large-scale university 
of lines of authority; (2) the absence of deficiency of power to act; and (3) the resulting absence of reasonably clear policies and objectives.

(1) Any one who has held academic office in our universities within the last few years will understand what I mean when I speak of the steady erosion of traditional relationships of authority in the university. Indeed, words such as "leadership" and "authority" have recently acquired such an odour as almost to be unmentionable in polite academic society: one almost apologizes for using them. The "antileadership vaccine" of which John Gardner wrote so powerfully and perceptively a few years ago seems to have done its work only too well. Under the influence of certain extreme versions of "participatory democracy" the foundations of older and coherent systems of authority have been undermined: some quite strange and unworkable doctrines of accountability are prevalent. The case of the unlucky dean of my previous section is unfortunately not hypothetical : the situation I described is of frequent occurrence. The theoretical and practical confusions engendered by such views are one of the chief causes of the steady erosion of traditional centres of authority in the university. Robert Nisbet (an eminent sociologist and former Vice-Chancellor in the University of California) puts it in these words :

"Finally, no one can miss the extent to which "participatory democracy" in university affairs bas not only ... sapped the foundations of any coberent system of authority, but also created a setting of instant and cbronic politics that increasingly makes serious teaching and study impossible." 3

"Authority" entails much more than power; "legitimacy, stated or unstated, is of the essence." ${ }^{4}$ Legitimacy has nearly vanished, to be replaced more and more by litigation. We are experiencing "the steady increase... of that adversary type of relationship, one founded on the utilization of litigation, which one encounters wherever traditional, consensual relationships are undergoing severe change." 5 Nisbet is speaking of American scene, but Adell and Carter independently confirm it of the Canadian situation as well.

(2) Within the university, individual officers frequently lack power to discharge their responsibilities (now more onerous than ever) because of this displacement of legitimacy and authority. Simultaneously, the university as a whole has considerably less power than formerly to act and to adapt itself to change - this at a time when the rate of change is increasing exponentially.

Everyone looks in vain for "centres of power". Did university faculty members gain power through the Duff-Berdahl reforms? They do not think so; and they are quite right, except in the sense that they are more able than previously to block the exercise of administrative power. ${ }^{6}$ Nor do students think (and again rightly) that they have secured access to power. As for administrators, their power to act is sevarely eroded both from "below" and from "above". Power seems to be everywhere - and therefore 
effectively nowhere. The problem is not concentration of power but its dispersion. Inertia, incapacity to respond, is the inevitable outcome.

(3) Given this inertia, we should not be surprised to find a third factor operating to defeat accountability. Universities are largely unable to delineate their goals and objectives in such a way as to make them operationally significant. Normative platitudes exist aplenty ; statements which have operational bite and which, e.g., planners can confidently utilize, do not. Too often we talk of "objectives" in the abstract as though they existed in some Platonic heaven, merely awaiting grasp at our convenience. Whenever I hear talk about "objectives", I have learned to ask: "Whose objectives ?" Depending upon your level of analysis, you can find within the multiversity tens, or scores, or hundreds, or thousands of objectives - many in direct competition with one another. In the absence of some over-arching authority delineation of objectives in such a way as to make accountability genuinely possible seems beyond our attainment.

"But do not boards of governors still have powers ?" I consider that this assumption is also becoming an illusion. As an authoritative article by Lyman A. Glenny (formerly Executive Director of the Illinois Board of Education, now Associate Director of the Center for Research and Development in Higher Education at Berkeley) makes clear, power is more and more falling into the hands of what he calls "the anonymous leaders" of higher education. ${ }^{7}$ University bureaus of planning or of information and research; university budget analysts and officers; professional accrediting agencies; federal granting agencies; state-wide co-ordinating boards; state budget officers, etc., increasingly control the destiny of the American university - "private" as well as "public". Similar forces are at work in Canada, with the usual time lag between American and Canadian experience. Add to these factors the imminent development of collective bargaining; the increasingly marked trend to appeal decisions of a board of trustees to the courts ; the impact of increasing economic stringency, and the further draining away of power from its traditional loci becomes more and more inevitable. As a statement of fact Glenny's position may be overly stark as applied to the present Canadian scene ; but there can be no doubt as to the direction in which we are headed. His conclusion it worth noting:

"All these factors lead to the conclusion that the real leadersbip roles of the president and the board are so batlly eroded as to be, quite literally, gone. We need to recognize this fact and had bet:er apprise the public and the politicians of the people and agencies who should be held accountable for major decisions on higher education considering their powers and authority as against those of the institutional leadership. Until this is done adequately, all the constituents of the university will continue to be frustrated because their great expectations of leadership in policy formulation are directed at persons who are. no longer in positions to exercise it." 8

I certainly do not wish to imply that all of the-administrative and management troubles we must contend with arise from the above mentioned causes. I have been 
speaking so far chiefly about the causes of our incapacity to respond in a decisive way to our problems. The problems themselves arise from a multiplicity of causes. Some of them are local to the university - but not many are co confined. One local factor is that universities are in the painful process of collapsing from a wildly expansionist state to a "steady state". (One only hopes that we can somehow reach a "steady state" : it sounds so pleasant.) As we rocketed into the expansionist stage (in the 1960's) we experienced considerable turbulence. The turbulence of re-entry from the stratosphere will be much more serious : too many structural nuts and bolts have come loose in our spaceship since we left terra firma. Secondly, for a very long time any university system had considerable "slack" within it. By "slack" I do not mean "waste" - through there is a certain quantity of that in any university - but rather a reserve capacity to adjust to sudden changes. This slack has now tended to disappear, as budgets are tightened, staff-student ratios attenuated, support staff reduced, and the implications of tenure policy begin to bite. Local also to the university (at least to the Canadian university) is the peculiar and baffling "two-track system", as I call it : on the one hand, an administrative-managerial line (from staff members to department head to dean to vice-president to president to board) ; and on the other an "academic track" (from department councils to faculty councils to senate to board). At the best of times this double-track system invites confusion. Given some currently popular interpretations of "participatory democracy", and given our present many-dimensioned crisis, this two-track system has come under severe and increasing strain.

What is perhaps more important to note is that many of the woes afflicting the contemporary university are not local to it : they are positively endemic to all modern large-scale organizations. In many respects, governments seem to be in as bad a condition as universities. In becoming too large, organizations violate principles of scaling which operate in the social realm as well as in the physical and biological. Growth past a certain point point becomes positively dysfunctional : ecologists today are only repeating observations as old as Aristotle - indeed much older. ${ }^{9}$ Organizations have increased in complexity and multiplicity of functions as well as in mere size, to the point where, it is safe to say, no one person or body any longer commands a single, informed view of the whole. "Communication" becomes notoriously difficult and a topical subject of complaint. In seeking to cope with the complaint, we try to send more and more complex messages from one part of the "system" to another : this only results in more and more "noise" and less and less "signal". The effort to widen the base of understanding and of advisory participation in university affairs (which was one of the main and legitimate thrusts of the Duff-Berdhal report) is throttled at its inception by such "noise". Finally, both universities and government cling to out-moded bureaucratic forms of organization. As Toffler (in company, with many other writers on organizations) has pointed out, bureaucracy "may be ideally suited to solving routine problems at a moderate pace. But when things speed up, and the problems cease to be routine, chaos breaks loose." 10 Characteristically, that sub-system which is the least stable tends to dominate the whole. ${ }^{11}$ 
What is the upshot of all this ? Simply, I think, that multiversities cannot continue to be what they are and survive. Here, for example, is a summary of a remarkable address by Dr. Robert Morse to the March 1971 meeting of the American National Research Council. (I must note that Morse is a physicist of wide reputation; a former university department head and dean; a senior administrator in government; a former president of Case Western Reserve. He is now a happy refugee from the academic scene, at the Woods Hole Oceanographic Institution.) The summary is as follows :

"Universities cannot be understood, says Robert Morse, recent president of Case Western
Reserve University, in a bit of bitter-sweet whimsy, unless we allow for the Second Law of
Thermodynamits, which, when expressed in bebavioral terms, says that it is easier to get
into trouble than to get out of it. Indeed, be contends universities are in deeper trouble
than they realize, for they have no real strategies for adapting to change, only tactics aimed
at simple survival. And he made clear, in an eloquent summary of the present state of
affairs... that universities, as they now exist, simply cannot survive more than a few more
years." 12

I have a whole battery of similar quotations, all from eminent scholars who have abandoned very high administrative posts in leading American universities. I must here content myself with only one further reference, again from Nisbet. Nisbet contends :

"The university in its present form is as nearly bopeless a structure as one can easily imagine. Its inner community and its traditional autbority, fragmented by the changes following World War II, its direct contribution to the social order a now visibly diminished one, its ancient dogma of knowledge for the sake of knowledge the object of derision, its curriculum and its sense of intellectual mission objects of contempt from both the political left and the right and - far, far worse - of spreading indifference inside and outside its walls (it is indifference, not anger or bate, that kills great institutions), the university in America today is plainly in as critical a position as was the guild or any knightly, aristocratic order in post-Reformation Europe." 13

\section{The University and Society}

Meanwhile, in spite of all these internal difficulties, the cry that universities must become "accountable" to "society", or to the "public", or to "government continues unabated. But how responsible and informed are these cries? How far are they justified, and how far not? Again, this is a complex topic; but some things need to be said, if only briefly.

In defence of universities, first, it needs to be emphasized that in our relationships to society, or to governments, some of the basic conditions of accountability are not present, and are not within the power of the university alone to establish. We cannot well avoid the use of a convenient abstraction such as "society", for example, but it is well to remember that (at least in our pluralistic context) only "societies" exist. Here we have not one "client" but a multiplicity of clients, frequently demanding mutually incompatible services of the university. Every professional association, for instance, typically clamours that the university strengthen (and perhaps substantially enlarge) that sector in which it is especially interested. Yet the university cannot reasonably 
be expected to satisfy such a host of competing interests, particularly in a period of severely straitened resources, both capital and operating.

As for "government", most of us are affected by two governments - federal and provincial - who do not necessarily see eye to eye and who in consequence have not adequately clarified their expectations of the role of the university. Even within the context of a provincial system, "government" does not always speak with a single voice : governments are not monoliths. One arm of government, without prior consultation, may face us with a demand that we enlarge the functions of a given faculty ; another, that we cut it back. One arm of government, again without adequate consultation, may sweep out of existence old modes of articulation between secondary and post-secondary systems. In the next breath, the university finds itself accused of failure to articulate with the secondary system - where permissiveness as to curricula and standards seems to have gone so far as to render the process of university admissions a positive nightmare. Unlike a nightmare, however, nowadays this process is costing real money.

We are constantly being told that we must be "effective" and "efficient" in the use of our ressources. We cannot be "effective", however, without some tolerably clear notions of what our "product" is to be. Is it mere numbers of graduates in such and such sectors? Or is it that we are to achieve a certain quality as well ? If the latter, are we to take as our aim a level of quality that is, so to speak, absolute ? Or a level relative to the capacity and training of those we admit? A "value-added" approach to education would suggest the latter alternative. Yet without an adequate measure of the level of attainment of students as they enter (and because of sweeping changes in the secondary system such a measure is now much harder to secure than formerly) and some index of their level as they leave, we can scarcely measure the "value added". "Efficiency", which is a relation between inputs and outputs, thereby eludes our grasp in at least one more important aspect. (In certain other respects, we frequently do far better than we get credit for.)

I am not here advocating that we should seek from governments an undue specification of our objectives. Over-specification of objectives, as I have been at pains to stress, is incompatible with the very notion and purpose of accountability. In the interests both of government and of the university much must be left unspecified. What I am saying is that accountability is always a two-way street; and that a good deal of the current criticism of the failure of universities to be accountable is in justice not to be laid exclusively upon their shoulders.

\section{The Responsibility of Universities}

Yet to pretend that universities have in no way "failed in accountability" (that is, in the proper discharge of their "duty and trust"), is fatuous in the extreme - and dangerous to boot. In some obvious ways we are not "efficient" in the use of our resources. I give one illustration only : that of the immense amount of time devoted by 
members of academic staffs to departmental, faculty and university "academic administration". At the time of the A.U.C.C. Cost Study of 1966-67, the amount of staff time devoted to this function seems to have been on average of the order of perhaps $15 \%$. Post Duff-Berdhal, decision-making has become so complex that this figure must now be much higher. Perhaps in the order of $20 \%$ or more would be a reasonable guess. Nothing very satisfactory to anybody seems thereby to be produced. Add in all of the indirect costs of this investment of staff time; assume that perhaps $50 \%$ of this investment is really unnecessary in that it is largely unrelated to the existing academic objectives of the institution in teaching, research and other functions; and you will find a wastage of some tens of millions of dollars across the nation. (I would wager that in business, industry and government there are quite comparable or worse wastages ; but it is the university situation I am currently describing.) Again, in many ways universities are probably not very "effective", for the simple reason that we frequently do not know what it is that we are trying to do, and have not seriously tried to find out, in sufficiently close (and embarrassing) analytical detail.

In response to external criticisms which, whether we like it or not, are going to be pressed very hard, we adopt unduly defensive postures which give excellent promise of being suicidal. After all, reality may be a useful crutch - if we want to move and if we need assistance; but the reality of our crisis is still appallingly remote from the consciousness of many academics. The tragedy is that because of our apparent internal paralysis and our failure to adapt to changing circumstances, a great deal that is of value, and of immense value, in universities as we have known them is in imminent danger of being destroyed.

Let me give another example which will probably set every academic nerve in the audience painfully throbbing. I refer to the question of control of research in the university. Our general philosophy of research has hitherto been largely laissez-faire. We have assumed that if every researcher "does his own thing", the workings of an "invisible hand" will assure maximum benefits to all concerned. But now we are faced with some painful choices. If our total resources are to be frozen or even to contract; and if one sector of our enterprise continues to develop according to laissez-faire principles, then some other sector (such as "teaching") is bound to suffer. Students, government commissions, and many members of the public obviously do believe that teaching has suffered. There is no point in our emphasizing in reply what is indubitably true, namely, that without an adequate amount of research and scholarly activity teaching as we know it in the university will wither and decline. The question which will not be put down by this response remains: How much research and of what kind and at what cost is truly necessary to keep teaching vital ? How much is of a type or range which, while perhaps valuable in itself, goes beyond that important function? "What is the proper balance between teaching and research ?" is a question every government or governmental commission is asking us. If we say in response that all of the research now carried on in our institutions is essential to the quality of teaching, we are saying 
something that nobody will find credible. If we concede that much of it is not essential to teaching, we shall find little safety for ourselves in complaining that we have no idea - not even an approximate idea - of how to cost such non-teaching oriented research. In dodging these problems, we are merely inviting some external body to impose arbitrary figures and assumptions upon us. If some of our genuine values are destroyed in this process, we shall have no one to blame but ourselves: "Forced relevance" - to use an ominous phrase which crept into one of the meetings of the Bonneau-Corry Commission - is hardly an attractive fate : it is about as appetizing as the "forced freedom" of Rousseau and his contemporary disciples of "participatory democracy." 14

\section{Is Whirl to be King?}

"Zeus is dethroned, and Whirl is King," says one of the characters in The Clouds. Like Aristophanes, we live in an age where Zeus - reason, order, authority is displaced by Whirl, by vortices of frenetic activity in which we are caught but of which we have small comprehension and even less control. There are times when one is impelled to cry: "Stop the whirl - I want to get off !"

Like other institutions the university is caught in a vortex of social, political, economic and technological forces so bewildering as to defy analysis. Yet in spite of this vortex into which we are drawn, lectures are still being given, research pursued and students trained and educated for professional careers or other useful stations in life. Our predicament is that these traditional, central values are threatened by the inability of the system as a whole to escape the vortex and to move with resolution on a course of its own volition.

It should be apparent that I am not about to propound any easy, instant answers to problems so vexing as to have caused many men of great ability, experience and dedication to throw up their hands in despair. Optimism in our circumstances is simpleminded euphoria. Pessimism, however, is not a policy one can willingly embrace.

What at this juncture is chiefly necessary is to recover our nerve and our resolution to act. A rout in battle is stopped only when first one man takes a stand, then a second and a third, and so on until the ranks are reformed. If we can summon such resolution, we can then address ourselves (in truly. rigorous fashion) to the first question of planning: Where are we now ? In consequence of such analysis - which if not both thorough and painful will be absolutely useless - we shall be able to face the second and third questions : Where do we want to go ? and : How do we get there ?

I am willing to postulate that if we do not commit ourselves to resolute action, we shall eventually be met half-way by society and government. The present surge of hostility toward the university may thereby be checked, and sensible accommodations arrived at. Much of our former autonomy will vanish : our decision boundaries are going to be severely constricted. Of this development I think there can be no doubt. In the fact of these changes our task is to define and to preserve at all costs our inner core of 
values while surrendering much that is peripheral and accidental. It is in such action that we shall fulfil "the mandate of accountability" and meet the legitimate expectations of Canadian society.

Notes

1. Adell, B. I., and Carter, D. D. Collective Bargaining for University Faculty in Canada. (A study commissioned by the Association of Universities and Colleges of Canada, and published by the Industrial Relations Centre, Queen's University, Kingston, Ontario, 1972.)

2. In developing this analysis, I have been greatly helped by comments from two colleagues in Philosophy : Professor R. H. Vincent of the University of Manitoba and Professor J. T. Stevenson of the University of Toronto.

3. Nisbet, Robert. The Degradation of the Academic Dogma (New York: Basic Books Inc., 1971), p. 222.

4. Ibid., PP. 43-44.

5. Ibid., pp. 137-138.

6. See the remarks of Dr. J. A. Corry, cited in Adell and Carter, p. 20 :

"Much of the substance of power in the university has been taken out of the president's office and away from the board of governors. The members of the academic, staff now bave what bas been taken out, and they bave nearly a veto on the use of what is left. They may find this bard to believe, but this is true. The battle is over."

7. Glenny, Lyman A. "The Anonymous Leaders of Higher Institutions." Institutional Research and Institutional Policy Formulation (11th Annual Forum of the Association for Institutional Research, 1971).

8. Ibid., p. 12.

9. "To the size of states there is a limit, as there is to other things, plants, animals, implements; for none of these retain their natural power when they are too large or too small, but they either wholly lose their nature, or are spoiled." (Aristotle, Politics, 1326 a 34, in the Oxford translation.)

For a recent exploration in some depth of the problem of scaling in the contemporary university, see an interesting article by J. A. Gallant and J. W. Prothero, 'Weight-Watching at the University: The Consequences of Growth", in Science, Vol. 175, (January, 1972), pp. $381 \mathrm{ff}$.

10. Toffler, A. Future Sbock (Toronto: Bantam Books of Canada, 1970), p. 139.

11. Ibid., p. 476.

12. See Bevan, William, "Science in the Universities in the Decade Ahead." American Scientist, Vol. 59 (November-December, 1971), p. 681. The views expressed by Bevan (former VicePresident and Provost of the Johns Hopkins University) are similar to those of Morse :

"Given the financial outlook for institutions of higher learning in the years immediately abead, given the enrolment picture for the eighties, given the national scientific and technical manpower needs for this same future period, and given the change in value structure that appears to be occurring within our society, universities cannot continue to be what they are and survive. I can make some besitant guesses about what they could become. What they will become may, of course, be quite another matter."

13. Op. cit., p. 236.

14. See the remarks by Dr. A. W. R. Carrothers, in The University of Calgary Gazette (Vol. 1, No. 20, February 10, 1972), p. 4. 